\title{
Pengembangan Laboratorium Virtual untuk Simulasi Uji Penetrasi Sistem Keamanan Jaringan
}

\author{
FahruRoszyMahtuf ${ }^{1}$,Puspanda Hatta ${ }^{2}$, EndarSuprih Wihidiyat ${ }^{3}$ \\ ${ }^{1}$ roszy_fahru@student.uns.ac.id, ${ }^{2}$ hatta.puspanda@staff.uns.ac.id, ${ }^{3}$ endars@staff.uns.ac.id \\ Pendidikan Teknik Informatika, Fakultas Keguruan dan Ilmu Pendidikan, Universitas Sebelas Maret
}

\begin{abstract}
This study aims to develop a virtualizationbased laboratory for simulating penetration tests and comparing the level of performance between physical servers and virtual servers. Development of a virtual laboratory using the VmwareWokstation hypervisor. Penetration simulation testing uses the Information System Security Assessment Framework (ISSAF) guidelines while the Tools used for testing penetration simulations use tools provided in Kali Linux. This study shows that the stages of penetration testing can be done in a virtual environment. Based on the results of the performance level testing shows a comparison of the two server response time levels is quite significant while for physical server throughput 10 times faster than virtual servers. Comparison of $\mathrm{CPU}$ enhancements on both servers is also quite significant inversely proportional to the comparison of memory usage on virtual servers 2 times greater than physical servers
\end{abstract}

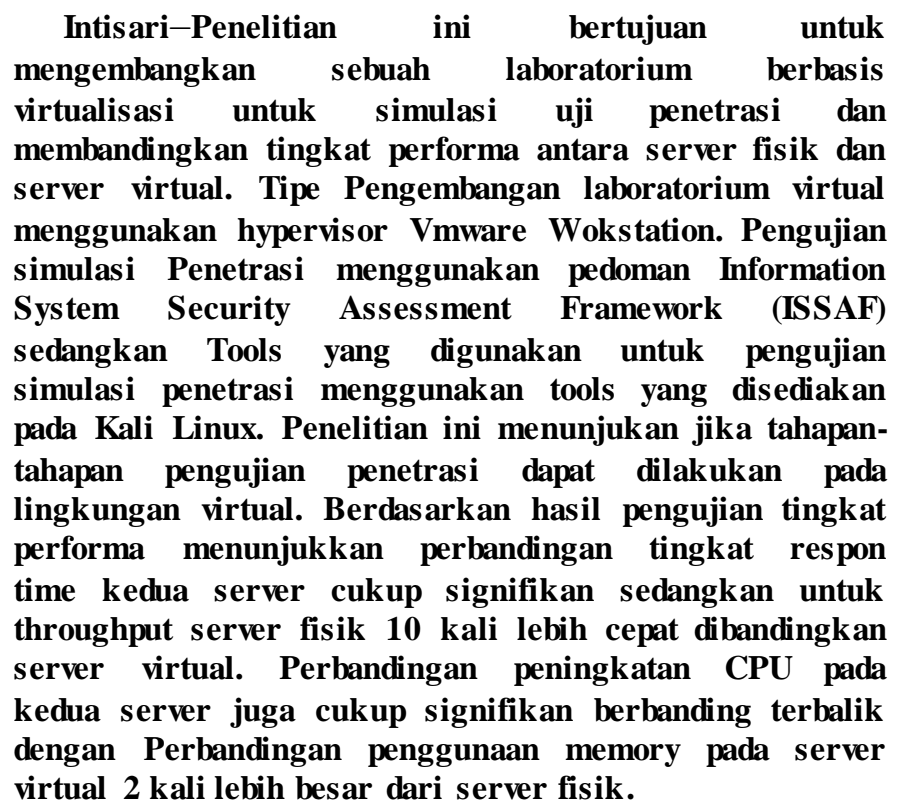

Kata Kunci- Virtualisasi, Virtual Server, ISSAF, UjiPenetrasi, Vmware Workstation.

\section{PENDAhuluan}

Kejahatan dunia maya (Cybercrime) adalah aktivitas kejahatan dengan komputer atau jaringan komputer yang digunakan sebagai alat dan sasaran terjadinya kejahatan. Data yang dipeloreh pada tahun 2011 kejahatan dunia maya berhasil mencapai angka 520 kasus dan tahun 2012 meningkat menjadi 600 kasus [1]. Untuk memahani pentingnya keamanan sistem perlunya pembelajaran berdasarkan pengalaman yang terkait dengan aksi atau pembelajaran praktis [2]. Pengalaman laboratorium merupakan faktor kunci dalam teknis dan pendidikan ilmiah. Keamanan jaringan dapat dipelajari pada kondisi riil maupun kondisi simulasi.

Kondisi simulasi yang dimaksud adalah kondisi non fisik atau pada kondisi lingkungan virtualisasi. Laboratorium virtual telah diusulkan untuk mengurangi biaya dan menyederhanankan pemeliharaan fasilitas dengan tetap memberikan siswa akses pada sistem yang nyata [3].Laboratotium virtual memberikan banyak manfaat, sumber daya sistem komputer dapat dimanfaatkan secara lebih efektif, beberapa lingkungan dapat dikonfigurasi dengan cepat dan mudah [4].Laboratorium virtual memastikan tidak ada aktivitas pengujian mencapai world wide web yang mencegah aktivitas pengujian secara tidak sengaja menjadi illegal[5].

Pengujian yang dilakukan pada server fisik meliputi pengujian vulnerability dan penetration testing. Tujuan pengujian adalahmenentukan dan mengetahui macam-macam serangan yangmungkin dilakukan pada sistem serta akibat yang bisa terjadikarena adanya kelemahan keamanan pada sistem komputeratau jaringan yang dimiliki[6]. Laboratorium virtual akan dikembangkan untuk melakukan simulasi pengujian vulnerability dan penetration testing pada lingkungan virtualisasi.

Laboratorium virtual yang dikembangkan untuk simulasi penetration testing memliki dua server virtual yaitu Metasploitable dan Windows Server 2008. Metasploitable digunakan untuk pengujian penetration testing sedangkan windows server 2008 digunakan sebagai web server. Perbandingan pengujian antara server fisik dan server virtual terdapat pada jumlah server yang digunakan. Pengujian vulnerability dan penetration testing pada server fisik memerlukan minimal dua buah server fisik yang digunakan, sedangkan pada server virtual hanya membutuhkan 1 server fisik dan didalam server fisik terdapat beberapa server virtual.

Pengujian penetrasi dan pengujian kerentanan adalah analisis sistematis dari status keamanan sistem informasi pada 
server. Pengujian penetrasi merupakan praktik pengujian pada sistem komputer, jaringan dan aplikasi web untuk menentukan kerentanan yang dapat digunakan untuk dimanfaatkan oleh penyerang[7].

Mempelajari etika teknik peretasan menjadi komponen penting dari program keamanan informasi yang bertujuan untuk menghasilkan para professional keamanan informasi yang kompeten[7].

Pengembangan virtual server untuk uji penetrasi memiliki hasil yang cukup baik. Hal ini dibuktikan dengan pengujian penetrasi pada lingkungan virtual menggunakan Oracle VM Virtual Box. Pengujian dilakukan dengan membandingkan hasil exploit sistem server virtual dengan metaploit dan armitage. Hasil penelitian menunjukan metasploit dan armitage dapat melakukan uji penetrasi pada lingkungan virtual [8].

Penelitian lain yang dilakukan dengan mengembangkan kurikulum penetration testing baru sebagai modul pembelajaran. Media yang digunakan untuk melakukan latihan modul penetration testing menggunakan virtual laboratorium. Berdasarkan feedback dari siswa $67 \%$ setuju memahami konsep dari penetration testing.[9].

Penelitian lain dilakukan dengan mengembangkan laboratorium virtual sebagai media belajar kurikulum keamanan informasi. Pengembangan virtual server yang dilakukan menggunakan VMware wokstation, pengujian yang dilakukan hanya melakukan scanning kerentanan pada server [10].

Dari beberapa penelitian ditunjukkan bahwa uji penetrasi pada lingkungan virtual dapat dilakukan dengan baik [7][8][9]. Maka dari itu penelitin ini bertujuan untuk membangun laboratorium virtual (virtual server) untuk simulasi uji penetrasi dengan metode penetration testing. Penelitian juga menambahkan pengujian untuk mengukur perbandingan antara server fisik dan virtual. Perbandingan yang digunakan adalah perbandingan penggunaan resource CPU dan Memory. Penelitian juga membandingkan tingkat Respon Time dan Throuhput.

\section{METODE PENELITIAN}

\section{Alur Penelitian}

Dalampenelitianini,terdapat alursebagaipedomandalam pengerjaan penelitian ini. Penelitian ini menggunakan ISSAF 0.2.1B tentang metodologi penetration testing. ISSAF memiliki beberapa kelebihan kontrol keamanan. ISSAF memiliki struktur yang jelas dan intuitif yang memandu penguji melalui langkah-langkah yang rumit [11]. Metodologi ini menjelaskan proses pengujian penetrasiyang optimal untuk membantu penguji melakukan pengujiansecara lengkap dan benar, menghindari kesalahan yangumumnya terkait dengan strategi serangan yang dipilih secaraacak Diagram penelitian ini dapat dilihat pada Gambar 1.

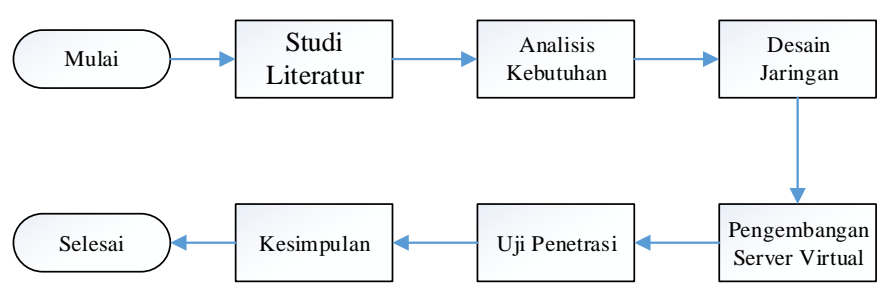

Gambar.1 Diagram Alur Penelitian

\section{Desain Topologi}

Topologi jaringan terdiri dari satu perangkat komputer atau laptop yang terhubung langsung dengan internet. Komputer berfungsi sebagai Host Os yang digunakan untuk menginstall Hypervisor. Hypervisor yang digunakan untuk pengembangan laboratorium virtual adalah VMware Workstation yang berfungsi sebagai tempat untuk membangun virtual server pada server fisik. Topologi jaringan pengembangan virtual server digambarkan pada Gambar 2.

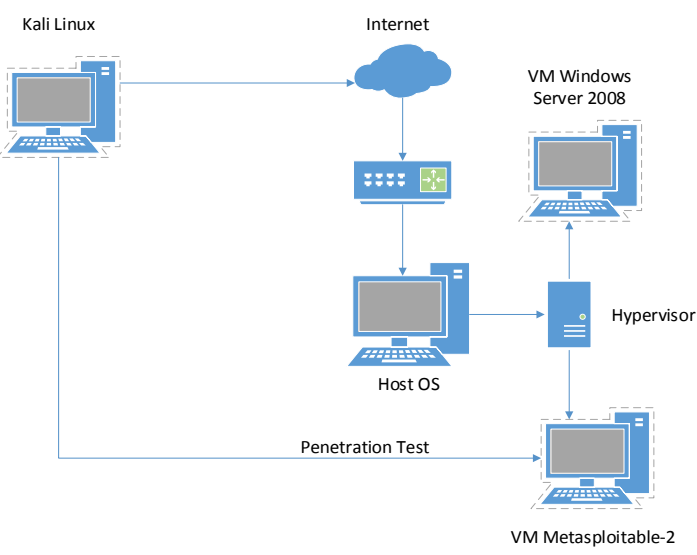

Gambar.2 TopologiJaringan

Pada Gambar 2 Topologi Jaringan, pengembangan laboratorium virtual menggunakan teknik virtualisasi tipe II yaitu hypervisor VMware Workstation berjalan diatas sistem operasi. Laboratorium virtual yang dikembangkan memiliki 2 buah virtual machine yang akan dikembangkan yaitu Metasploitable-2 dan Windows Server 2008. Kali Linux digunakan sebagai komputer penyerang karena memiliki tools-tools peretasan yang lumayan lengkap.

\section{Tahap Uji Penetrasi}

Pada tahap ini dilakukan uji penetrasi pada server virtual yang sudah dikembangkan. Server yang digunakan untuk target uji penetrasi adalah metasploitable-2 karena dikhususkan untuk latihan uji penetrasi dan komputer penyerang menggunakan kali linux. Tahap pengujian penetrasi dibagi menjadi 5 yaitu tahap awal adalah mengumpulkan informasi, pemetaan jaringan, indentifikasi kerentanan, 
eksploitasi, mendapatkan akses dan password cracking. Tahapan uji penetrasi dapat dilihat pada Gambar.3.

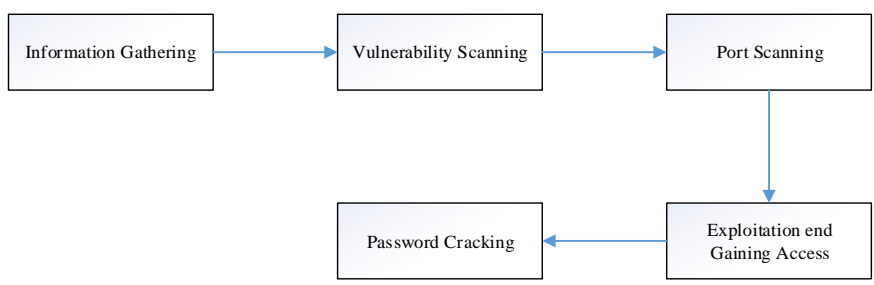

Gambar.3. Tahap Uji Penetrasi

\section{Uji Kinerja Server}

Selain pengujian uji penetrasi, kinerja dari server virtual yang dikembangkan perlu diuji untuk memperoleh data yang dapat digunakan untuk melakukan perbadingan dengan server non virtual. Pengujian kinerja server dilakukan untuk mengukur nilai Respon Time, Throughput, penggunaan Memory dan penggunaan CPU. Data yang diperoleh digunakan untuk melakukan perbandingan antara server virtual dan server non virtual. Pengujian dilakukan dengan mengirimkan 10 paket pada server dengan beban yang berbeda pada setiap paket yang dikirim.

\section{HASIL DAN PEMBAHASAN}

Penetration testing menunjukan hal-hal yang dilakukan sebelum dan proses pengujian keamanan pada server. Pada penelitian ini pengujian penetrasi berfokus pada technical control assessment. Berikut merupakan tahapan pada pengujian penetration testing yang dilakukan.

\section{Information gathering}

Tahap information gathering ini digunakan untuk mencari informasi awal yang dibutuhkan untuk melakukan tahap selanjutnya. Informasi yang dibutuhkan berupa ip address dari server metasploitable-2. Ip address yang didapatkan digunakan untuk melakukan vulnerability scanning dan port scanning,information gathering yang dilakukan menggunakan tools netdiscover. Hasil dari information gathering dapat dilihat pada Tabel.2.

Tabel 2. Hasil Information gathering

\begin{tabular}{|l|c|}
\hline \multicolumn{1}{|c|}{ IP } & At Mac address \\
\hline 192.168 .76 .1 & $00: 50: 56: \mathrm{c} 0: 00: 08$ \\
\hline 192.168 .76 .2 & $00: 50: 56: \mathrm{e} 7: \mathrm{c} 0: \mathrm{b} 2$ \\
\hline 192.168 .76 .128 & $00: 0 \mathrm{c}: 29: 10: \mathrm{a} 0: 75$ \\
\hline 192.168 .76 .130 & $00: 0 \mathrm{c}: 30: 20: \mathrm{b} 0 ; 85$ \\
\hline 192.168 .76 .254 & $00: 50: 56: \mathrm{e} 8: \mathrm{bd}: 47$ \\
\hline
\end{tabular}

\section{Vulnerability scanning}

Tahap vulnerability scanning digunakan untuk mencari celah keamanan pada server metasploitable-2 dengan menggunakan ip address server 192.168.76.128 yang berhasil didapatkan pada tahap information gathering. Hasil pengujian berupa jumlah kerentanan sistem dan kerentanan web yang dapat ditemukan menggunakan tools Nessus. Hasil pengujian vulnerability dapat dilihat pada Gambar 4.

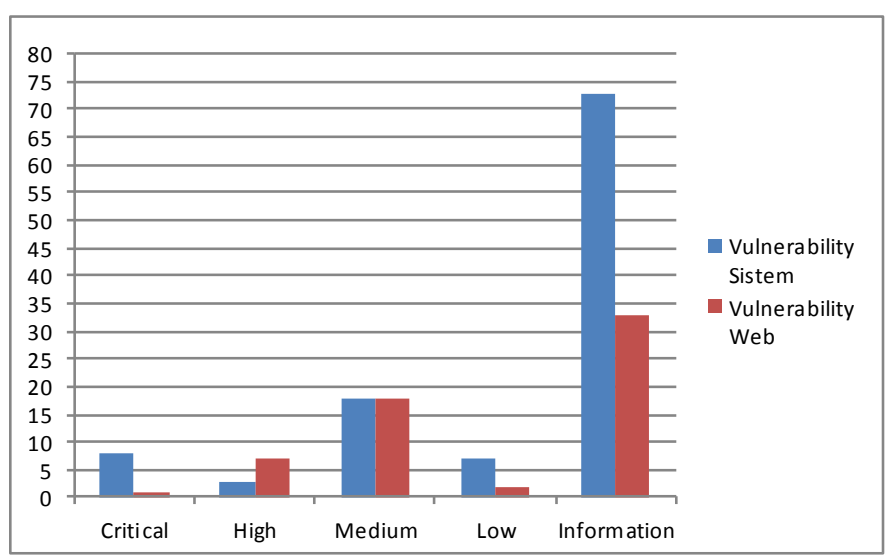

Gambar 4. Hasil Vulnerability scanning

Berdasarkan hasil pengujian pada Gambar.4, hasil analisis dari server metasploitable-2 memiliki kerentanan sistem 8 kerentanan tingkat kritikal, 3 kerentanan tingkat tinggi, 18 kerentanan tingkat medium, 7 kerentanan tingkat rendah, 73 kerentanan tingkat informasi. Kerentanan pada web yang ditemukan memiliki 1 kerentanan tingkat kritikal, 7 kerentanan tingkat tinggi, 18 kerentanan tingkat medium, 2 kerentanan tingkat rendah dan 33 kerentanan tingkat informasi.

\section{Port scanning}

Tahap port scanning bertujuan untuk menemukan celah keamanan yang berada pada server dengan mencari port yang berstatus terbuka pada server. Celah keamanan yang dicari pada tahap port scanning ada 4 jenis yaitu port, status, service yang berjalan dan versi dari sistem operasi yang digunakan. Celah keamanan yang ditemukan digunakan untuk melakukan peretasan pada sistem server. Celah keamanan juga digunakan untuk melakukan planning untuk menentukan jenis serangan dan tools yang akan digunakan untuk melakukan serangan pada sistem server. Proses tahap port scanning dapat dilihat pada Gambar 5.

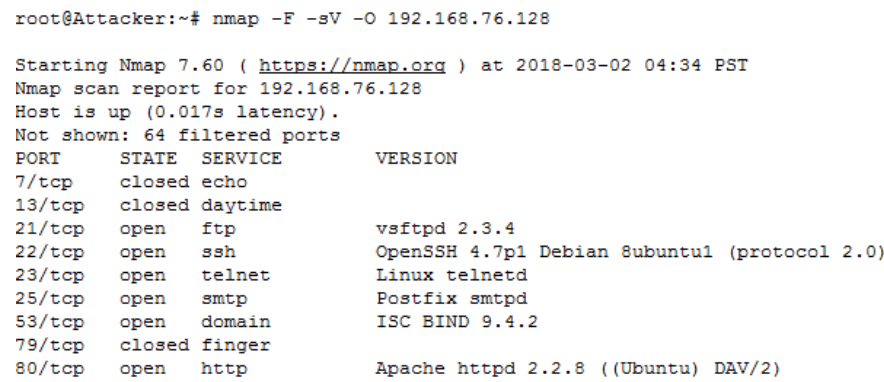

Gambar 5. Proses Port scanning 


\section{Exploitation dan Gaining access}

Tahap exploitation dan gaining access merupakan tahap yang bertujuan untuk masuk pada sistem server dan mencari informasi yang berada pada server. Tahap exploitation dan gaining acces dilakukan melalui celah keamanan atau kerentanan yang ditemukan pada tahap port scanning. Metode peretasan dan tools yang digunakan disesuaikan dengan celah atau kerentanan yang berhasil ditemukan. Salah satu proses tahap exploitation dan gaining access pada celah yang ditemukan pada phpmysql dapat dilihat pada Gambar 6 .

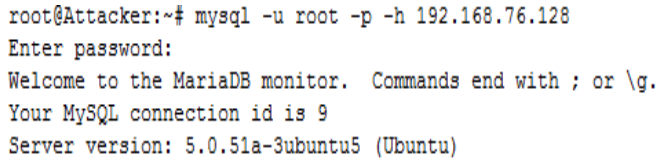

Gambar 6. Proses Exploitaion database MySQL

\section{Peretasan Password}

Tahap peretasan password merupakan tahapan tahapan mencari password yang berada pada server. Beberapa teknik dapat digunakan untuk melakukan tahap peretasan password antara lain : Dictionary attack, brute force, phising dan masih banyak teknik yang bisa digunakan. Tahap peretasan password dapat dilihat pada Gambar 7.

\section{rootQAttacker: $\#$ unshadow}

Usage: unshadow PASSWORD-FILE SHADOW-FILE

rootQAttacker: \# unshadow / root/Password/passwd/root/Password/shadow > mypassword

root@Attacker: $\approx$ john -show mypassword

0 password hashes cracked, 7 left

rootQAttacker: $\#$ john mypassword

Warning: detected hash type "md5crypt", but the string is also recognized as "aix-smd5"

Use the "--format=aix-smd5" option to force loading these as that type instead

Using default input encoding: UTF-8

Loaded 7 password hashes with 7 different salts (md5crypt, crypt(3) \$1\$ [MD5 128/128 AVX 4x3])

Press ' $q$ ' or Ctrl-C to abort, almost any other key for status

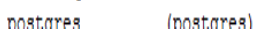

\section{Gambar 7. Proses Peretasan Password}

\section{Perbandingan Server Fisik dan Virtual}

Perbandingan antara server fisik dan server laboratorium virtual (virtual server) dilakukan dengan membandingkan respon time dan throughput antara web server yang berada pada server fisik dan server virtual. Pengujian dilakukan dengan mengirimkan paket request pada web server sebanyak 10 kali dengan jumlah request yang berbeda. Hasil pengujian respon time webserver dapat dilihat pada Tabel 3.
Tabel 3. Hasil Respone Time Webserver

\begin{tabular}{|c|c|c|}
\hline \multirow{2}{*}{ Httpef } & \multicolumn{2}{|c|}{ Respon Time (duration test/second) } \\
\cline { 2 - 3 } & Server Virtual & Server Fisik \\
\hline 100 & 9.932 & 9.901 \\
\hline 200 & 19.933 & 19.900 \\
\hline 300 & 29.928 & 29.901 \\
\hline 400 & 39.948 & 39.901 \\
\hline 500 & 49.915 & 49.981 \\
\hline 600 & 60.517 & 59.901 \\
\hline 700 & 69.928 & 69.901 \\
\hline 800 & 79.928 & 79.981 \\
\hline 900 & 91.351 & 89.902 \\
\hline 1000 & 102.109 & 99.901 \\
\hline
\end{tabular}

Berdasarkan Tabel 3, dapat diketahui respon time rata dari kedua webserver. Webserver pada server fisik memiliki ratarata respon time sebesar 54.912 dan webserver pada virtual server sebesar 55.349. Perbandingan rata-rata respon time antara server fisik dan server virtual cukup signifikan.

Tabel 4. Perbandingan Throughput Web Server

\begin{tabular}{|c|c|c|}
\hline \multirow{2}{*}{ Httperf } & \multicolumn{2}{|c|}{ Throughput (Kbps/s) } \\
\cline { 2 - 3 } & Server Virtual & Server Fisik \\
\hline 100 & 11.1 & 100.7 \\
\hline 200 & 11.1 & 100.1 \\
\hline 300 & 11.1 & 100 \\
\hline 400 & 11.1 & 107.9 \\
\hline 500 & 11.1 & 107.8 \\
\hline 600 & 11 & 107.8 \\
\hline 700 & 11.1 & 107.8 \\
\hline 800 & 11.1 & 107.7 \\
\hline 900 & 10.9 & 107.7 \\
\hline 1000 & 10.9 & 107.7 \\
\hline
\end{tabular}

Berdasarkan Tabel 4. hasil pengujian throughput pada Tabel 4 dapat diketahui perbedaan throughput antara server virtual dan server fisik. Perbandingan rata-rata throughput antara server virtual dan server fisik adalah $11.05 \mathrm{Kbps} / \mathrm{s}$ dan $105.52 \mathrm{Kbps} / \mathrm{s}$. Perbandingan rata-rata throughput server fisik 10 kali lebih cepat dibandingkan dengan server virtual.

Tabel 5. Perbandingan Memory Server Virtual dan Fisik

\begin{tabular}{|c|c|c|c|c|}
\hline \multirow{2}{*}{ Httperf } & \multicolumn{4}{|c|}{ Penggunaan Memory (Mb) } \\
\cline { 2 - 5 } & Virtual Server & $\%$ & Server Fisik & $\%$ \\
\hline 100 & 399.644 & 77.53 & 584.84 & 34.17 \\
\hline 200 & 404.476 & 78.47 & 585.468 & 34.21 \\
\hline 300 & 409.240 & 79.40 & 586.568 & 34.27 \\
\hline 400 & 407.936 & 79.14 & 587.176 & 34.31 \\
\hline 500 & 408.812 & 79.31 & 589.26 & 24.43 \\
\hline 600 & 410.432 & 79.63 & 590.62 & 34.51 \\
\hline 700 & 408.82 & 79.31 & 592.832 & 34.64 \\
\hline 800 & 408.944 & 79.34 & 594.112 & 34.72 \\
\hline 900 & 409.06 & 79.36 & 597.056 & 34.89 \\
\hline 1000 & 409.704 & 79.49 & 598.938 & 35 \\
\hline
\end{tabular}


Berdasarkan Tabel 5 perbandingan penggunaan memory pada saat pengujian menggunakan hhtperf dengan 10 kali pengujian dan beban request yang berbeda dapat dilihat penggunaan rata-rata memory server virtual $79.10 \%$ dan ratarata penggunaan memory pada server fisik $34.52 \%$. Perbandingan rata-rata penggunaan memory server virtual 2 kali lebih besar jika dibandingkan dengan penggunaan memory pada server fisik.

Tabel 6. Perbandingan CPU

\begin{tabular}{|c|c|c|}
\hline \multirow{2}{*}{ Httperf } & \multicolumn{2}{|c|}{ Penggunaan CPU (\%) } \\
\cline { 2 - 3 } & Server Virtual & Server Fisik \\
\hline 100 & 12 & 2.77 \\
\hline 200 & 12.3 & 5.77 \\
\hline 300 & 12.7 & 10.1 \\
\hline 400 & 13.3 & 14.29 \\
\hline 500 & 13.9 & 14.94 \\
\hline 600 & 14 & 14 \\
\hline 700 & 14.3 & 20.88 \\
\hline 800 & 14.9 & 22.48 \\
\hline 900 & 15.3 & 24.96 \\
\hline 1000 & 15.7 & 28.89 \\
\hline
\end{tabular}

Berdasarkan Tabel 6 Perbandingan peningkatan CPU dapat diketahui penggunaan rata-rata cpu pada server virtual $13.84 \%$ dan penggunaan rata-rata cpu pada server fisik $15.905 \%$. Perbandingan rata-rata penggunaan resource cpu pada server fisik dan virtual cukup signifikan jika dilihat pada Tabel 6.

\section{KESIMPULAN DAN SARAN}

Penelitian ini menunjukan bahwa simulasi uji penetrasi pada lingkungan virtual dapat dilakukan sesuai dengan tahapan uji penetrasi pada kondisi non virtual. Ini dibuktikan dengan tahapan - tahapan uji penetrasi berhasil dilakukan pada server virtual. Pada pengujian respon time dan penggunaan CPU pada server fisik dan virtual mempunyai perbedaan tingkat respon time dan CPU yang cukup signifikan, sedangkan pada pengujian throughput server fisik 10 kali lebih cepat dibandingkan throughput pada server virtual. Hal ini berbanding terbalik pada penggunaan memory, server virtual 2 kali lebih besar pemakaian memory dibandingkan pada server fisik. Berdasarkan hasil pengujian dapat ditunjukkan bahwa Teknik virtualisasi dapat dimanfaatkan untuk mengoptimalkan penggunaan cpu dan memory.

\section{DAFTAR PUSTAKa}

[1] Pirmansyah, "Analisis Persepsi Auditor Sistem Informasi mengenai Pencegahan atas Tindakan
Cybercrime.

[2] Moon,J. A Handbook of Reflective and Experiential Learning:Theory Falmer.pp.126.2004 andpractice.London:Routledge

[3] Wolf. Tilman, "Assessing Sudent Learning in Virtual Laboratory Environment. IEEE Transcalation on Education", Vol. 53, No.2, pp. 216-221, 2010.

[4] Bulbrook. Harry, "Using Virtual Machine to provide a secure Teaching Lab environmnet,". 2009.

[5] Arjun, CV 2017, 'Penetration testing: Vulnerability analysis in a virtual environment'Journal of Engineering and Applied Sciences, vol. 12, no. Specialissue9, pp. 8723-8729. DOI: $10.3923 /$ jeasci.2017.8723.8729

[6] Trabelsi Z. and McCoey M., "Ethical hacking in information security curricula," International Journal of Information and Communication Technology Education (IJICTE), Vol. 12, Issue 1, pp. 1-10, 2016.

Ankita Gupta, Kavita, kirandeep Kaur."VulnerabilityAssessment and Penetration testing”. Computer ScienceDepartment, PEC University of Technology, India*Electronics and Electrical Communication Depertement,PEC University of Technology, India IJETT Vol 4Issue3 2013

[8] S. Christoper, Z. Janusz, Penetration testing in a Virtual Environment. CNT 4104 Fall Networks, 2011

[9] Li, C. (2015). Penetration testing curriculum development in practice. Journal of Information Technology Education: Innovations in Practice, 14, 85-99. Retrieved from http://www.jite.org/documents/Vol14/JITEv14IIPp085099Li1014.pdf

[10] Bulbrook.H, "Using Virtual Machine to provides a secure Teaching Lab Environment."

[11] Hutagalung. R. H, Nugroho. L. E and Hidayat. R, "Analisis Uji Penetrasi Menggunakan ISSAF", ISSN : 2338 - 0276, 2017.

\section{T. Edition, Top-Down Network Design.}


